\title{
Processing of High Performance Composites Based on Peek by Aqueous Suspension Prepregging
}

\author{
Liliana Burakowski Nohara ${ }^{\mathrm{a}, \mathrm{b}, *}$, Michelle Leali Costa ${ }^{\mathrm{a}, \mathrm{b}}$, Mauro Angelo Alves ${ }^{\mathrm{b}}$, \\ Marta Ferreira Koyama Takahashic, Evandro Luís Nohara ${ }^{\mathrm{d}}$,Mirabel Cerqueira Rezende \\ ${ }^{a}$ Faculty of Engineering, Department of Materials and Technology, \\ Universidade Estadual Paulista - UNESP, \\ CEP 12516-410 Guaratinguetá, SP, Brazil \\ ${ }^{\mathrm{b}}$ Materials Division, Department of Aerospace Science and Technology, \\ Institute of Aeronautics and Space, CEP 12228-904 São Paulo, SP, Brazil \\ ${ }^{\circ}$ Chemistry Division, Department of Aerospace Science and Technology, \\ Institute of Aeronautics and Space, CEP 12228-904 São Paulo, SP, Brazil \\ ${ }^{\mathrm{d}}$ Department of Mechanical Engineering, University of Taubaté - UNITAU, \\ CEP 12060-440 São Paulo, SP, Brazil
}

Received: February 4, 2010; Revised: May 24, 2010

\begin{abstract}
The use of polyamic acid (PAA) precursor as interphase in polymer composites is one of the many applications of polyimides (PIs). In this work, composites based on poly(ether-ether-ketone) (PEEK) and carbon fibers were prepared using two manufacturing techniques for thermoplastic composites: hot compression molding, and aqueous polymeric suspension prepregging using PIs as interphase. Two PAAs were synthesized and used as interphases: 3,3'-4,4'-benzophenonetetracarboxylic dianhydride/oxydianiline (BTDA/ODA) and pyromellitic dianhydride/ oxydianiline (PMDA/ODA). The PAA/PI systems were analyzed by differential scanning calorimetry (DSC), thermogravimetry (TGA), Fourier transform infrared spectroscopy (FTIR) and nuclear magnetic resonance (NMR). Results from these analyses confirmed the synthesis of these compounds. Aqueous polymeric suspension prepregging was more efficient than hot compression molding when the PMDA/ODA PAA/PI interphase was used; also, the interlaminar shear strength of composites produced using this technique was $14.5 \%$ higher than the one produced using hot compression molding.
\end{abstract}

Keywords: carbon fiber, interphase, thermoplastic polymer

\section{Introduction}

Poly(ether-ether-ketone) (PEEK) polymer is a tough, semicrystalline and poorly soluble material with high melting temperature. Its crystallinity contributes to its excellent chemical resistance, mechanical properties and high service temperature. This combination of physical and chemical properties is desirable for engineering and structural applications ${ }^{1-3}$.

The processing of PEEK is difficult due to its chemical and solvent resistance, and high melting temperature $\left(\mathrm{T}_{\mathrm{m}}\right)$. The dissolution of polymers such as PEEK requires high temperatures and corrosive solvents, which can damage the carbon fibers used in composites during impregnation ${ }^{1}$.

Interactions in the interphase region in semicrystalline thermoplastic composites depend on many factors such as matrix morphology, fiber surface conditions, presence of residual stresses, fiber and matrix elastic moduli as well as the presence of reactive functionalities. These functionalities can be obtained by coating the reinforcement or treating its surface with an interfacial bonding agent ${ }^{3}$.

Polyimides (PIs) are a class of thermally stable high-performance polymers that continue to gain importance in a wide variety of applications such as high-temperature adhesives, microelectronics, membranes, photosensitive materials, matrix materials for composites and as reinforcement coating ${ }^{3-9}$.

These applications are possible due to the many advantageous properties exhibited by polyimides, including excellent mechanical, thermal and adhesive properties, good radiation and chemical resistances, and low dielectric constant ${ }^{9-12}$.

In the case of composite applications, PIs have been successfully used as reinforcement coating and interface between carbon fibers and high-performance thermoplastic matrices such as PEEK, poly(etherimide) and poly(phenylene sulfide) ${ }^{13}$.

Recently, it has been possible to use PIs as interface in structural thermoplastic composites by employing a new pre-impregnation and composite manufacture technique, namely, aqueous suspension prepregging ${ }^{14-16}$. With this technique has been possible to improve the mechanical and chemical properties of the interface in thermoplastic composites.

The aqueous suspension prepregging technique uses polyamic acid (PAA), a polyimide precursor, allowing the polymer matrix to be applied to the reinforcement together with the interphase-forming 
polymer during a single pre-impregnation $\operatorname{step}^{17}$. The aqueous suspension prepregging technique uses PAA neutralized with a base to produce the PAA salt.

The polymer matrix (powder form) is then dispersed in an aqueous solution of the PAA salt, which acts as a dispersant and electrostatically stabilizes the suspension via the interaction with the surface of the matrix powder particles ${ }^{14,18}$. Carbon fibers or fabrics are then coated with the polymer suspension. After drying the water produced by the prepregging, a heating cycle is used to convert the PAA into PI by imidization ${ }^{14,18,19}$.

Few studies in literature have described the processing of high performance thermoplastic composites by aqueous suspension prepregging. A major concern of the engineer interested in the practical applications of polymeric composite materials in structural components is the significant discrepancies between physical, chemical, and mechanical properties that have been reported by different investigators in studies carried out under different conditions. Consequently, there is reduced confidence and constraints on the projects using these materials.

Thus, the aim of the present study was to compare two techniques used to prepare thermoplastic composites, namely hot press molding and aqueous suspension prepregging. Three composites were prepared: one was prepared from pure PEEK powder (hot press molding); two others were prepared using modified PEEK (aqueous suspension prepreging). Aqueous suspension prepreging uses PAA, a PI precursor, based on 3,3'-4,4'-benzophenonetetracarboxylic dianhydride/oxydianiline (BTDA/ODA) and pyromellitic dianhydride/ oxydianiline (PMDA/ODA) as interphase in the composite material. This technique improves the wettability of the fiber surface by the matrix and is an alternative to increase the adhesion between these materials. The interlaminar shear strength (ILSS), an important property of the composites, was also measured and compared.

\section{Experimental}

\subsection{Materials}

\subsubsection{Carbon fiber}

A polyacrylonitrile-based plain-weave carbon fabric (Hexcel Composites) with sizing compatible to epoxy resin was used in the experiments. This fabric is made of continuous yarns consisting of 3,000 filaments with a diameter of about $7 \mu \mathrm{m}$ each. For the experiments, small square pieces $(50 \times 50 \mathrm{~mm})$ were cut from the fabric and washed with acetone to eliminate sizing.

\subsubsection{Polymer matrix}

PEEK, a semi-crystalline thermoplastic, is marketed by ICI under trade name Victrex 450G in powder form and beige color. The glass transition $\left(\mathrm{T}_{\mathrm{g}}\right)$ and the melting point $\left(\mathrm{T}_{\mathrm{m}}\right)$ temperatures of PEEK are 145 and $340{ }^{\circ} \mathrm{C}$, respectively. The processing window of PEEK ranges from 380 to $400{ }^{\circ} \mathrm{C}$; its structure is shown in Figure 1 .

\subsection{Methods}

\subsubsection{Synthesis and PIs precursors characterization \& PIs selected to improve PEEK processability}

\subsubsection{Synthesis of PAA and PIs}

Two polyimides were synthesized, BTDA/ODA (Figure 2a) and PMDA/ODA (Figure $2 b$ ), using the procedure described in literature ${ }^{5,6,20}$. Equimolar amounts $(0.004 \mathrm{~mol})$ of PMDA and BTDA<smiles>CCOc1ccc(Oc2ccc(C(=O)c3ccc(C)cc3)cc2)cc1</smiles>

Figure 1. Chemical structure of PEEK ${ }^{2,15}$.<smiles>Cc1ccc(Oc2ccc(N3C(=O)c4ccc(C(=O)c5ccc6c(c5)C(=O)N(C)C6=O)cc4C3=O)cc2)cc1</smiles>

(a)

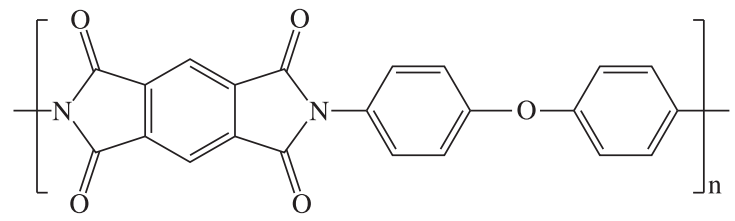

(b)

Figure 2. Chemical structure of the PI: a) BTDA/ODA and b) PMDA/ $\mathrm{ODA}^{7,9}$.

dianhydride (Sigma Aldrich) and ODA diamine (Alfa-Aesar) were dissolved in acetone (Merck). After solubilization, dianhydride was added to diamine under argon atmosphere at room temperature, and an ultrasonic mixing device was used to stir the solution for 4 hours at $40 \mathrm{~Hz}$. Monofunctional end-capper phthalic anhydride (PA) (Vetec) was added to solution $\left(16.10^{-5} \mathrm{~mol}\right)$. The reaction was completed after conversion of the reagents BTDA+ODA and PMDA+ODA to PAA. This step was confirmed using thin layer chromatography. Subsequently, PAA precipitation occurred and the solvent was removed using a rotary evaporator.

The PAA and PIs obtained were analyzed by DSC and TGA (thermal properties); FTIR (confirmation of conversion PAA into PI) and NMR (functional group identification in PAA and PIs).

\subsubsection{Characterization of the polyimides}

\section{Differential Scanning Calorimetry (DSC) and Thermogravimetric Analyses (TGA)}

A DSC instrument (DSC Pyris 1, Perkin Elmer) was used to find Tg of synthesized PIs. Samples weighed about $13 \mathrm{mg}$ and the analysys was carried out at a $10{ }^{\circ} \mathrm{C} / \mathrm{min}$ heating rate under nitrogen purge $(20 \mathrm{~mL} / \mathrm{min})$. Temperature and heat flow were calibrated using indium and zinc standards.

The poly(amic acid) precursor was converted to polyimide following the thermal imidization cycle: heating of the sample at a rate of $10{ }^{\circ} \mathrm{C} / \mathrm{min}$, from room temperature to 100,200 and $300{ }^{\circ} \mathrm{C}$, each temperature step was held for 60 minutes.

Thereafter, the now imidized samples were:

- BTDA/ODA system: cooled at $100{ }^{\circ} \mathrm{C} / \mathrm{min}$ to $150{ }^{\circ} \mathrm{C}$ and heated to 400 at $20{ }^{\circ} \mathrm{C} / \mathrm{min}$;

- PMDA/ODA system: heated from 300 to $550{ }^{\circ} \mathrm{C}$ at $20^{\circ} \mathrm{C} / \mathrm{min}$.

A TGA instrument (TGA-7HT, Perkin Elmer) was used to evaluate the thermal stability of the polyimides. The analysis was carried out under nitrogen purge $(20 \mathrm{~mL} / \mathrm{min})$ and a heating rate of 
$10{ }^{\circ} \mathrm{C} / \mathrm{min}$. PAA samples weighing about $26 \mathrm{mg}$ each were subjected to the same thermal cycle described above (imidization).

Following cooling at room temperature, the samples now weighing about $22 \mathrm{mg}$ each were heated once more, this time up to $1000{ }^{\circ} \mathrm{C}$, to determine the temperatures at which each polymer degraded. The weight loss of the samples was measured as a function of temperature.

Fourier Transform Infrared Spectroscopy

Fourier Transform Infrared Spectroscopy (FT-IR) was used to confirm the presence of functional groups within both poly(amic acids) and polyimides. Measurements were carried out on a FT-IR spectrometer (Spectrum 2000, Perkin Elmer) using the potassium bromide disk technique (1:400 mg).

\section{Nuclear Magnetic Resonance}

Solid-state ${ }^{13} \mathrm{C}$ Nuclear Magnetic Resonance (NMR) was used to confirm PAA/PI synthesis through the identification of chemical structures. Measurements were carried out with a Varian Unity $300 \mathrm{MHz}$ NMR spectrometer. The ${ }^{13} \mathrm{C} \mathrm{CP/MAS} \mathrm{(Cross} \mathrm{Polarization} \mathrm{Magic} \mathrm{Angle}$ Spinning) spectra were recorded at $74.5 \mathrm{MHz}$. The samples were packed into a zirconia rotor and the spinning rate was $4 \mathrm{kHz}$. Contact times of $1200 \mathrm{~ms}$ and relaxation between pulses of 5 seconds were used to obtain appropriate relaxation for all carbon types. Solid-state NMR was used because of the difficulty in solubilizing PIs.

\subsubsection{Preparation of composites by hot compression molding}

With neat PEEK

- The preparation of composites using hot compression molding consisted in spreading the powdered polymer matrix over the carbon fabric, as shown in Figure 3. In an appropriate mold, layers of carbon fabric were intercalated with polymer layers in the ratio reinforcement:matrix of 50:50 (v/v).

With PEEK and PIs

- Poly(amic acid) salt preparation: Solutions of PAA-BTDA/ ODA and PAA-PMDA/ODA with ammonium hydroxide $\left(\mathrm{NH}_{4} \mathrm{PAA}\right.$ salt) were prepared in the stoichiometric ratio of 1.25:1 for the PAA functionalities (two per unit). For this purpose, $\mathrm{NH}_{4} \mathrm{OH}$ (Synth) was used with deionized water and titrated to $28-30 \%$. This solution had a $\mathrm{pH}=12$.

- Prepregging suspension preparation: A polymer suspension was prepared by first adding PAA to the $\mathrm{NH}_{4} \mathrm{OH}$ solution $(\mathrm{pH}=12)$.

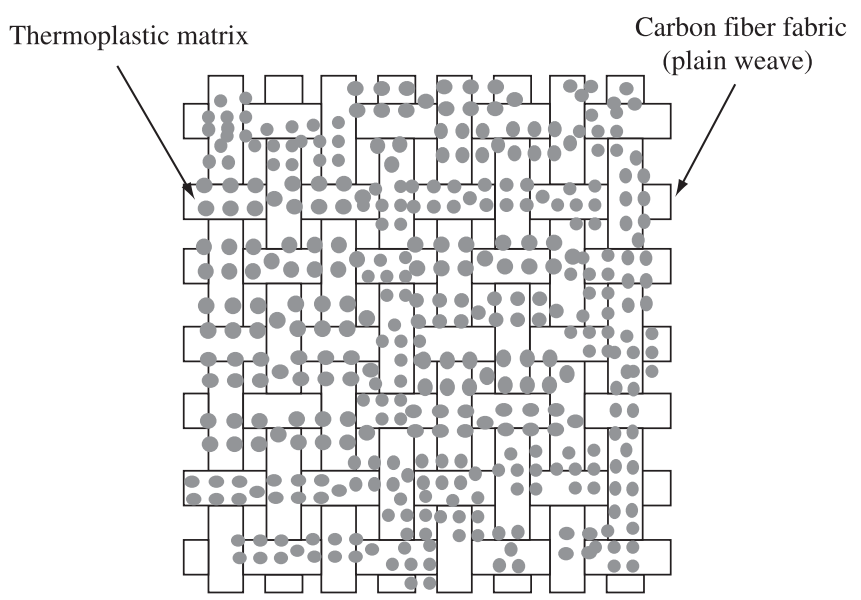

Figure 3. Schematic diagram showing the carbon fiber weaving pattern and the polymer matrix of the composite processed with the hot compression molding method.
Following, a beaker containing the $\mathrm{NH}_{4} \mathrm{PAA}$ salt was covered with plastic film and heated to $60{ }^{\circ} \mathrm{C}$ for 30 minutes while being stirred with a magnet bar. The solution was then cooled at room temperature.

After this step, PEEK powder was added to the $\mathrm{NH}_{4} \mathrm{PAA}$ solution, and the mixture was homogenized with a magnetic stirrer for 30 minutes to assure contact between PEEK particles and the polymer dispersant. The mass ratio $\mathrm{NH}_{4} \mathrm{PAA} / \mathrm{PEEK}$ was 0.05 and PEEK mass concentration in the solution was $10 \%$, in agreement to the literature ${ }^{15}$.

\subsubsection{Preparation of laminates}

The fabric pieces, cut in squares $(50 \times 50 \mathrm{~mm})$, were dipped into the beaker containing the polymer suspension and stirred continuously; the pre-impregnated fabric pieces were then kept at room temperature for 24 hours. After, the fabric pieces were placed in a vacuum oven where they were thermally imidized according to the thermal imidization cycle described previously. This procedure removed about $99 \%$ of the water physically bonded to the pre-impregnated pieces. Following, 18 layers of the pre-impregnated material were stacked in the same mold used to prepare the hot compression molding specimens.

The molds containing the specimens obtained by hot compression molding and aqueous suspension prepregging techniques were heated from room temperature to $400{ }^{\circ} \mathrm{C}$ at a heating rate of $10{ }^{\circ} \mathrm{C} / \mathrm{min}$.

The samples were kept at $400{ }^{\circ} \mathrm{C}$ for 60 minutes; during the first 30 minutes at atmospheric pressure, and the last 30 minutes at 9.8 MPa. The composites were allowed to cool under pressure $(9.8 \mathrm{MPa})$ at room temperature. The composites were produced in the ratio reinforcement: matrix of 50:50 (v/v).

\subsubsection{Mechanical characterization - Interlaminar shear strength tests}

Interlaminar shear strength (ILSS) was measured by short beam method, conducted according to the ASTM D 2344-84 ${ }^{21}$. The testing was carried out in an Instron universal testing machine, the test speed was set at $1.3 \mathrm{~mm} / \mathrm{min}$ and a load cell of $5 \mathrm{t}$ was used. Ten specimens of each batch of composites prepared were tested. ILSS values were calculated using the formula ${ }^{21}$ :

$$
F^{s b s}=0,75 \times \frac{P_{m}}{b \times h}
$$

(Equation 1)

where $F^{\text {sbs }}$ is the short-beam strength $(\mathrm{MPa}), P_{\mathrm{m}}$ is the maximum load during the test $(\mathrm{N}), b$ and $h$ are the specimen width $(\mathrm{mm})$, and thickness $(\mathrm{mm})$, respectively.

\section{Results and Discussion}

The synthesized PAAs had different colors; BTDA/ODA was yellow and PMDA/ODA was golden yellow. The results from the characterization of the PAAs and PIs using DSC, TGA, FT-IR and NMR are presented below.

\subsection{Characterization}

\subsubsection{PIs characterization}

3.1.1.1. Differential scanning calorimetry and Thermogravimetric analyses

The conversion of PAA to polyimide was analyzed by DSC and TGA. Figure 4 shows DSC and TGA curves of thermally cured BTDA/ODA and PMDA/ODA. 


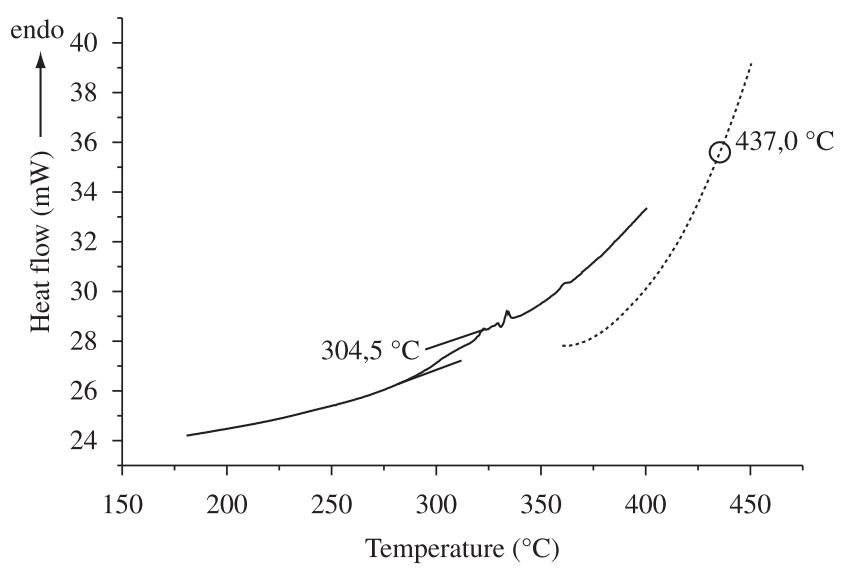

(a)

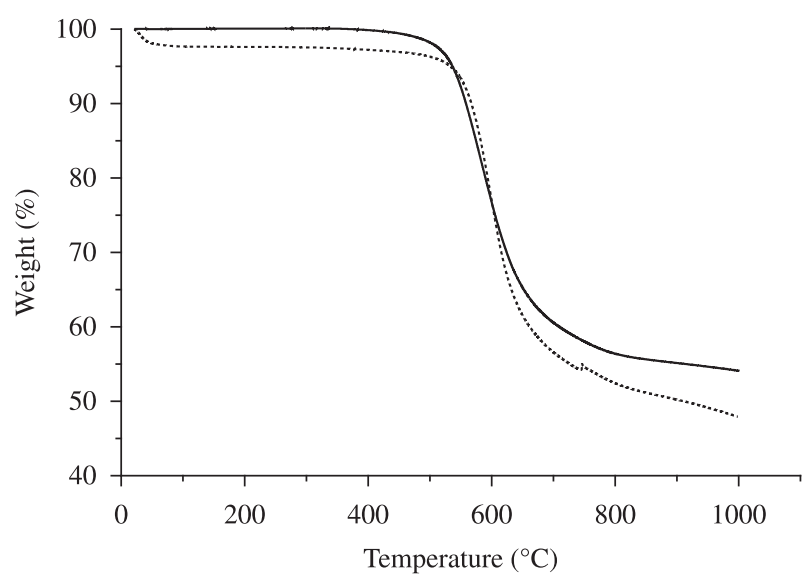

(b)

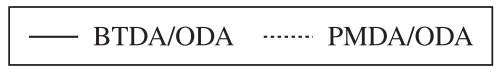

Figure 4. a) DSC and b) TGA curves for PI BTDA/ODA and PMDA/ODA.

The measured glass transition temperature, $\mathrm{T}_{\mathrm{g}}$, of BTDA/ ODA and PMDA/ODA was 304.5 and $437.3{ }^{\circ} \mathrm{C}$, respectively. The literature reports different $\mathrm{T}_{\mathrm{g}}$ values for BTDA/ODA, e.g., 279 and $329{ }^{\circ} \mathrm{C}^{7,20}$. These differences indicate that solvents, temperature and methods (solution, chemical or thermal) used for the imidization influence the thermal properties of the synthesized polyimide. In the case of PMDA/ODA polyimide, $T_{g}$ was measured in the first scan because of its high value, which was above the imidization temperature.

The high Tg value of the PMDA/ODA polyimide is attributed to the presence of carbonyl groups attached to the same benzene ring (Figure 2), and also to the number of benzene rings (PMDA, one ring; BTDA, two rings), causing this polyimide to have a more rigid structure compared to the BTDA/ODA polyimide.

The thermal stability of the polyimides was evaluated by TGA (Figure 4b). A first scan was performed to eliminate water from the preceding synthesis and imidization process. The sample was then allowed to cool to room temperature. The sample, now weighing about $22 \mathrm{mg}$, was again subjected to heating, this time to $1000{ }^{\circ} \mathrm{C}$, for the identification of the temperature at which the polymer begins to degrade.

The thermal degradation of the BTDA/ODA and PMDA/ODA polyimides began at 422 and $498{ }^{\circ} \mathrm{C}$, respectively. Char yield at $1000{ }^{\circ} \mathrm{C}$ was about 54 and 48 wt. (\%) for the PMDA/ODA and BTDA/ ODA polyimides, respectively.

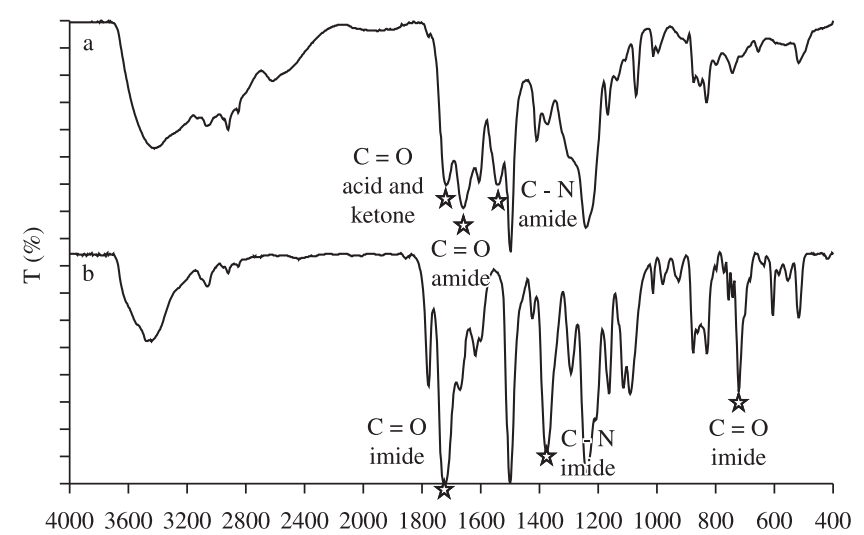

$\mathrm{cm}^{-1}$

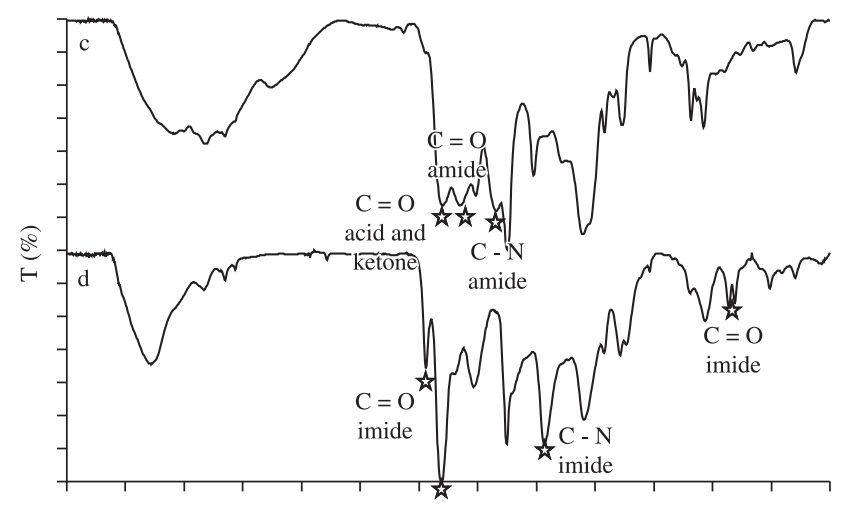

$40003600320028002400200018001600140012001000 \quad 800 \quad 600 \quad 400$

$\mathrm{cm}^{-1}$

Figure 5. Infrared spectra of PAA and PI. a) and b) BTDA/ODA; c) and d) PMDA/ODA.

\subsubsection{Fourier transform infrared spectroscopy}

Figures $5 \mathrm{a}$ and $\mathrm{b}$ show the absorption spectra of from BTDA/ ODA. Figures $5 \mathrm{c}$ and $\mathrm{d}$ show the absorption spectra of PAA and PI obtained from PMDA/ODA.

Similar absorption bands were observed for both polyamic acid samples (BTDA/ODA and PMDA/ODA) (Figures 5a and c). Bands near $1719 \mathrm{~cm}^{-1}$ were assigned to the vibrational modes of acid groups for both samples. Bands near 1660 and $1537-1542 \mathrm{~cm}^{-1}$ were assigned to the vibrational modes of amide groups.

The bands related to acid and amide groups disappeared after imidization. The characteristic absorption bands of imide groups near $1778,1722-1724,1377$ and $721-725 \mathrm{~cm}^{-1}$, were present in the spectra (Figures $5 \mathrm{~b}$ and $\mathrm{d}$ ). These absorption bands confirm the presence of imide groups.

\subsubsection{Nuclear magnetic ressonance}

${ }^{13} \mathrm{C} \mathrm{CP/MAS} \mathrm{NMR} \mathrm{experiments} \mathrm{were} \mathrm{performed} \mathrm{to} \mathrm{identify}$ protons and carbon atoms in the structure of the PAA and PIs samples. Solid state ${ }^{13} \mathrm{C}$ NMR was chosen because of the insolubility of PIs in known solvents, which makes liquid state ${ }^{13} \mathrm{C}$ NMR difficult.

The assignment of signals in the spectra of solid samples is usually made by comparing typical chemical shift values $(\delta)$ based on the interpretation of solution-state chemical shift values. However, it is well known that the chemical shift of solids can be significantly different than those of liquids. This phenomenon may be of particular importance in 
the study of polyimides, where interchain charge transfer interactions can contribute to the solid state chemical shifts ${ }^{22}$.

It is worth pointing out that while it is possible to identify regions in the spectra that are indicative of the presence of aromatic components, it may be difficult to precisely identify the location of primary, secondary (among others) carbon atoms. Figures 6 and 7 show the main carbon atoms identified in the spectra together with the corresponding chemical structure.

The spectra of the PAA and PI samples of the BTDA/ODA type are shown in Figures $6 a$ and $b$. The identification of the conversion of PAA into PI is demonstrated by the disappearance of the peak corresponding to the carbon of the $\mathrm{COOH}$ group, and the appearance of a peak corresponding to the carbon of the NCO group. The displacement of the peak corresponding to $\mathrm{C} 1$ in Figure $6 \mathrm{a}$<smiles>Cc1ccc(Oc2ccc(NC(=O)c3ccc(C(=O)c4ccc(C(=O)NC(C)C)c(C(=O)O)c4)cc3C(=O)O)cc2)cc1</smiles>

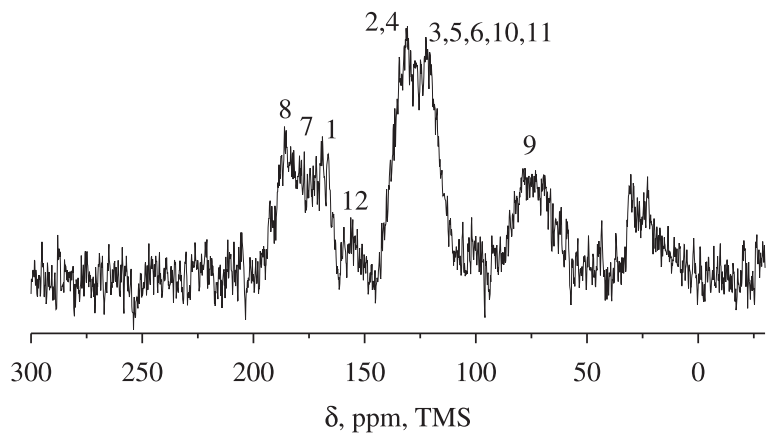

(a)
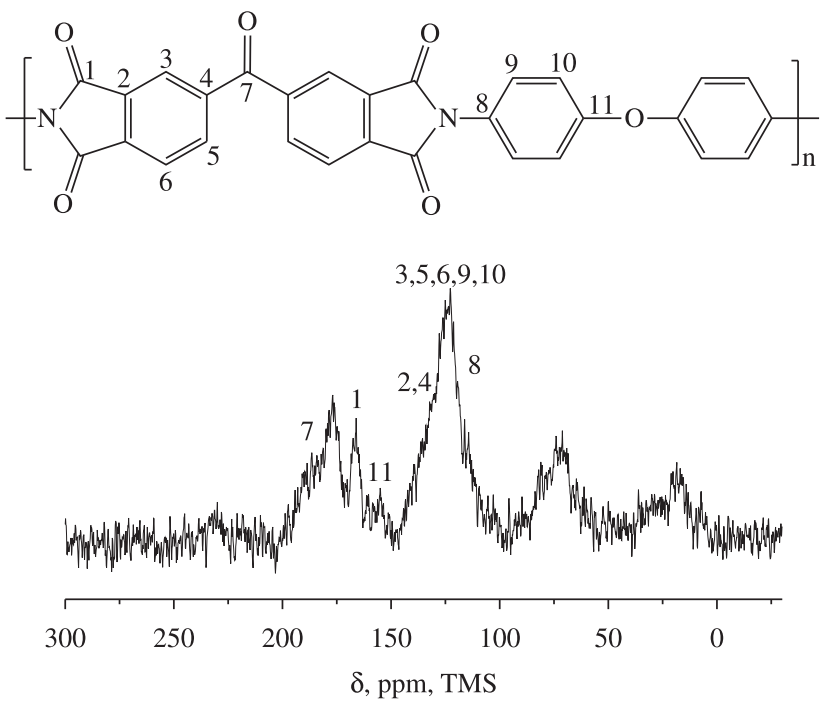

(b)

Figure 6. ${ }^{13} \mathrm{C}$ NMR spectra: a) PAA - BTDA/ODA and b) PI-BTDA/ODA.
( $\delta=160-220)$ to a lower value $(\delta=163-172)$, Figure $6 \mathrm{~b}$, indicates that the conversion of the PAA precursor to the PI polymer indeed occurred.

Another way to detect the occurrence of imidization is by measuring the displacement of the peaks produced by carbon atoms of the C-N $(\delta=60-80 \mathrm{ppm})$ and $\mathrm{NCO}(\delta=163-172 \mathrm{ppm})^{22}$ groups, but in this study such measurement was not possible because the comparison of spectra shows that in this region $(\delta=100-150 \mathrm{ppm})$ several other peaks produced by different types of carbon atoms can be found ${ }^{23}$ and many of them probably superpose each other.

One may consider that the peak at 75 ppm shows a change with respect to its original aspect, evidenced by a narrowing of the band and a decrease of the peak amplitude, which is an indication that the peak produced by the carbon atom of the $\mathrm{C}-\mathrm{N}$ group was changed.

It was verified that one of the main changes that occurred in the chemical structure during the conversion from PA to PI of the PMDA/ ODA type was the elimination of the carbon of the $\mathrm{COOH}$ group, which has chemical shift in the range 160-220 ppm, and the appearance of a carbon atom of the NCO group with $\delta=163-172 \mathrm{ppm}^{22,23}$.

Indeed, the disappearance of a narrow peak with $\delta=177 \mathrm{ppm}$ belonging to a carbon atom of the $\mathrm{COOH}$ group (indicated in Figure 7a, spectrum and structure, by "1") and the appearance of the carbon atom of the NCO group (indicated in Figure 7b, spectrum and structure, by " 1 ") is an indication that the PAA was converted into PI.

\subsubsection{Composites evaluation}

\subsubsection{Evaluation of composite preparation techniques}

Two processing techniques were employed to produce composites using PEEK thermoplastic matrix: hot compression molding and aqueous suspension prepregging technique. Consequently, three composites were prepared: one from pure PEEK powder (hot compression molding composite) and others two with modified PEEK (aqueous suspension prepreging composites). The latter technique uses a "bonding agent" between the reinforcement and the matrix; the laminates obtained by this technique were evaluated with respect to adhesion and the ease of handling during prepegging.

\subsection{With neat PEEK - Hot compression molding technique}

The production of composites by hot compression molding technique consisted in spreading the powder polymeric matrix over the intercalated carbon fiber cloth pieces in an adequate mold. After consolidation of the laminate, the specimens were cut according to the ASTM D 2344-84 specifications $^{21}$.

\subsection{Aqueous suspension prepregging technique}

The polymer dispersants adsorbed on the PEEK polymer particles contributed to the aggregation reduction of PEEK particles, decreasing the viscosity of the suspension.

After impregnation, the carbon fiber fabric pieces were kept at room temperature for 24 hours to dry. The adhesion of the matrix powder to the reinforcement was checked before the thermal imidization in a conventional oven. The results of the interaction between the poly(amic acids), the reinforcement and the matrix are described below.

The color of the PEEK polymer suspension prepared from the PAA salt of BTDA/ODA type changed from yellow to orange-yellow, while the pure poly(amic acid) and PEEK matrix were beige. The color change can probably be attributed to the formation of a charge 
<smiles>CCCCNC(=O)c1cc(C(=O)Nc2ccc(Oc3ccc(C)cc3)cc2)c(C(=O)O)cc1C(=O)O</smiles>

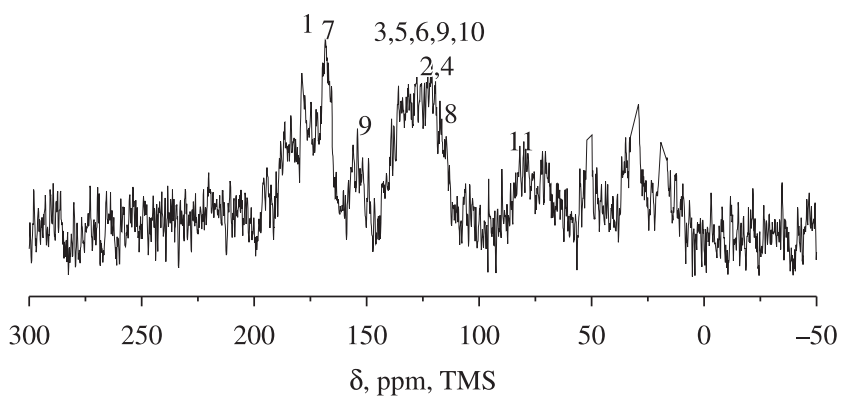

(a)
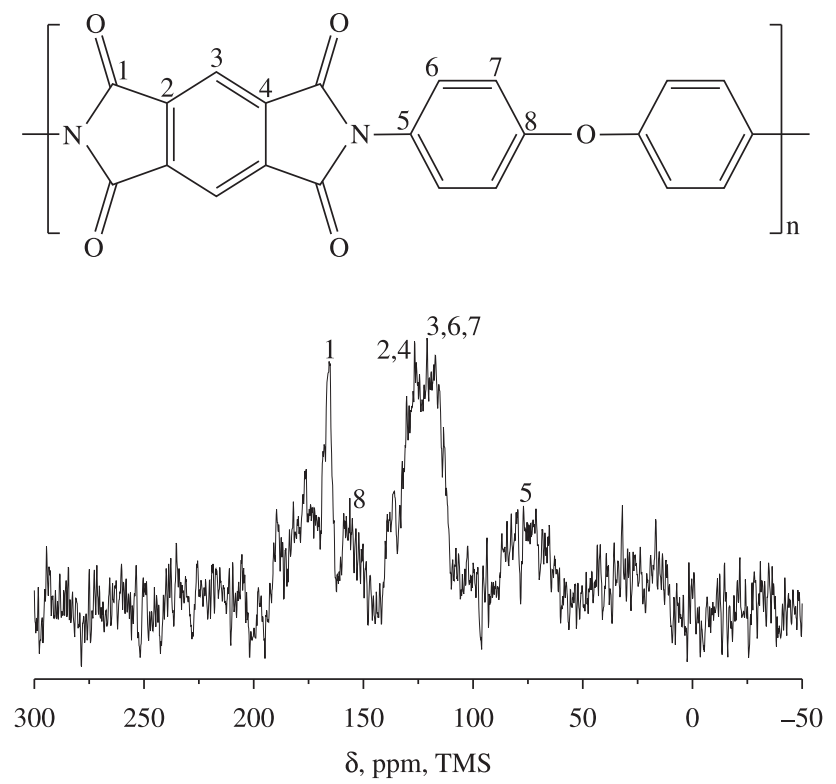

(b)

Figure 7. ${ }^{13} \mathrm{C}$ NMR spectra: a) PAA - PMDA/ODA e b) PI-PMDA/ODA.

transfer complex (CTC) between the dianhydride and diamine groups into pyromellitic diimides, as determined by Kotov et al. using UV spectroscopy ${ }^{24}$. These authors observed that the color of PI films was produced by intra- and intermolecular charge transfer interactions. The color of PI films is very sensitive not only to the structure of the reagents but also to other factors, such as the type of solvents, purity of the reagents, atmosphere and curing conditions. The color change in these materials is inversely correlated to the ionization potential of the diimides. These authors attribute these changes to the formation of CTC's. This phenomenon is related to Lewis acid-base type interactions. The occurrence of these electronic interactions, which are very strong in PIs, are responsible for the increase in color intensity.

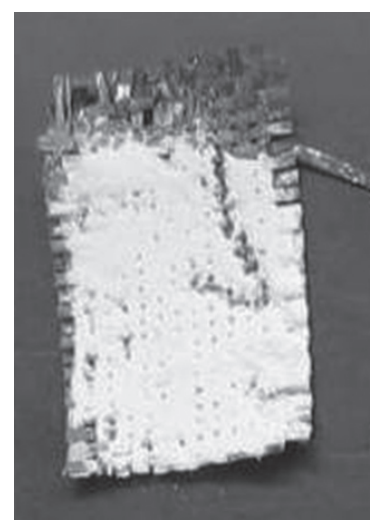

(a)

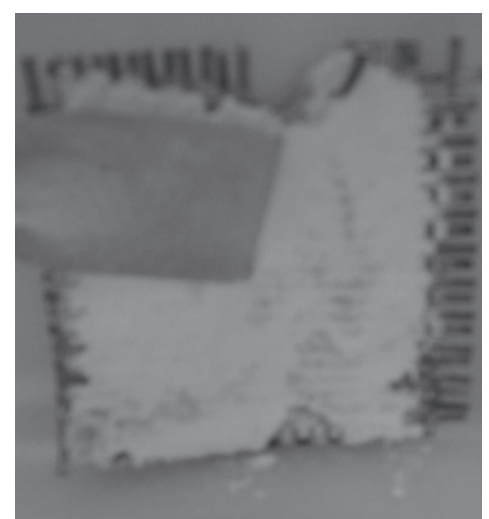

(b)
Figure 8. Carbon fabrics impregnated with PEEK polymer suspensions: a) with PAA BTDA/ODA interphase and b) PMDA/ODA interphase.

The colors of PEEK polymer suspensions prepared from the PAA salt of PMDA/ODA type were slightly faded compared to yellow, tending to a brownish tint, which is a characteristic of this PI.

This phenomenon can also be explained by the formation of a CTC between the dianhydride and diamine groups, which leads to the formation of pyromellitic diimides. The CTC is the main reason for the color of the completely aromatic PIs used in this study.

In a previous work $^{16}$, polymer solutions were prepared and analyzed with respect to $\mathrm{pH}$ changes and it was observed that suspensions with more intense colors had lower $\mathrm{pH}$ (11.7) and had a larger amount of polymer matrix in suspension compared to the ones with higher $\mathrm{pH}$ (12.3). This behavior is probably due to the charge equilibrium in the suspension or, in other words, to the number of base charges in equilibrium with PAA charges. That is, in higher $\mathrm{pH}$ solutions there are more charge from bases, which increases the charge imbalance, resulting in a larger amount of matrix deposited on the bottom of the container (when the suspension was at rest). However, it was observed that a $\mathrm{pH}$ between 11.7 and 12.3 did not affect the adhesion of matrix particles to the carbon fiber reinforcement. Thus, the suspensions used in this study had $\mathrm{pH}=12$.

\subsubsection{Laminate evaluation - PEEK matrix adhesion/ interface/reinforcement}

Visual inspection results of the carbon fiber fabric impregnated with PEEK polymer suspension, using PAAs based on BTDA/ODA and PMDA/ODA, are shown in Figures 8a and b, respectively. After PAA imidization in a conventional oven, PEEK pre-impregnated carbon fiber with corresponding PIs interfaces were obtained.

It was visually observed that after imidization the PEEK/ PAA systems adhered significantly to the carbon fiber fabric. It can be observed in Figures $8 \mathrm{a}$ and $\mathrm{b}$ that both systems improved the adhesiveness of the carbon fibers in such a way that the preimpregnated materials could be handled freely, enabling their stacking in the composite mold.

Figure $8 \mathrm{~b}$ shows a spatula being used to verify the adhesion (by means of the PI interphase type PMDA/ODA) of the polymer matrix to the carbon fiber fabric; it can also be seen in Figure 8b that the pre-impregnated materials were held vertically to facilitate the evaluation of the adhesion between components. It was necessary to use a spatula to separate the thin polymer layer adhered to the substrate since the matrix adhered satisfactorily and the material could be handled safely. 
Table 1. ILSS values of PEEK/carbon fiber thermoplastic composites obtained by hot compression molding and aqueous suspension prepregging method.

Interlaminar shear strength (ILSS) (MPa)

Hot compression molding technique

Composite reinforcement /matrix

$71.2 \pm 2$

Aqueous suspension prepregging technique

\section{PI-BTDA/ODA}

$74.2 \pm 2$

PI-PMDA/ODA

$81.5 \pm 3$

\subsubsection{Composite characterization - Interlaminar shear strength test}

In Table 1 are shown ILSS values, and respective standard deviations, of the three families of thermoplastic composites processed processed by hot compression molding technique (one composite) and by aqueous suspension prepregging (two composites).

Stress vs. strain curves, obtained in the ILSS tests, shows the occurrence of a non-catastrophic failure, meaning that the specimen did not break abruptly when the maximum stress value was reached. It was also observed that all specimens assayed for ILSS developed interlaminar fractures; cracks formed in the central region of the specimen in the horizontal direction and between the pre-impregnated material layers.

Comparing the ILSS values listed in Table 1 one observes that the composite obtained by pre-impregnation via polymer suspension had higher mechanical strength (74.2 and $81.5 \mathrm{MPa}$ for the samples obtained from PI BTDA/ODA and PI PMDA/ODA, respectively) than composites obtained by hot compression molding (71.2 MPa). These results confirm that the PI interphase, produced by the aqueous suspension prepregging, improved the interface between the fiber and the PEEK matrix.

The improved ILSS, observed in the composite using PMDA/ ODA PI as PEEK polymer matrix interface, is probably due to the more rigid structure of the dianhydride PMDA, which has only one phenylene group; BTDA, on the other hand, has two phenylene groups linked by a $-\mathrm{C}=\mathrm{O}$ bridge group.

Considering the similarities between the chain structure of the polyimides and PEEK one may assume that the rigid structure of the PMDA/ODA PI allowed its superposition onto the PEEK structure, which also has an aromatic structure ${ }^{9,25}$. Moreover, the PEEK structure has structural similarities to the ODA portion, allowing comparison of the aromatic ether group of the PEEK molecules.

Xiaohua et al. ${ }^{26}$ reported that there can exist charge transfer interaction between PI and PEEK. In the case of interaction between PI molecules, the charge transfer interaction occurs between the imide group and the PI p-phenylene group; while in the interaction between PI and PEEK molecules, the charge transfer interaction occurs between PI imide groups (electron donor) and the PEEK p-phenylene group (electron acceptor). According to these authors, the interaction between PEEK and PI is stronger than the interaction between PI molecules, showing that carbon fiber/PEEK interface can be improved by the use of aromatic PI.

\section{Conclusions}

In the present study two different processing techniques to manufacture composites based on PEEK matrix and carbon fabric were investigated: hot compression molding and aqueous suspension prepregging. For this purpose, synthesis of two different types of polyimides, BTDA/ODA and PMDA/ODA, was carried out. DSC and TGA thermal analyses, and FT-IR and NMR chemical analyses were used to confirm the synthesis of both PIs.
The carbon fabric impregnated with the PEEK polymer suspension and the PAA BTDA/ODA and PAA PMD/ODA presented good values of interlaminar shear strength suggesting a strong adhesion to the reinforcement/matrix, which may be indicative of good wettability. The same behavior did not occur for systems prepared by simply spreading the matrix onto the surface of the reinforcement (hot compression molding). The shear strength values obtained for the hot compression samples were lower than those of the aqueous suspension prepreging samples. This finding indicates that the PAA/PI acted as a bonding agent between the PEEK matrix and the carbon fiber improving the adhesion of matrix in reinforcement.

The composite manufactured by aqueous suspension prepregging technique exhibited higher interlaminar shear strength values when compared to hot compression molding composites. Also, better interface response was observed in PMDA/ODA PI because of its more rigid molecular structure as compared to BTDA/ODA PI. This result is probably due to the aromatic character of the structures of both PMDA/ODA and PEEK, which contributes for a superposition of the polymer chains and consequently an attraction between the two structures.

This study also showed that both PAA/PIs types, BTDA/ODA and PMDA/ODA, may be used in the manufacture of high-performance composites, as a coating for carbon fibers, as well as for the processing via aqueous suspension prepregging, since PI can withstand high temperatures compatible to this class of composites.

\section{Acknowledgments}

The authors would like to thank FAPESP (São Paulo Research Foundation) and CNPq (National Council for Scientific and Technological Development) (Proc. no. 150124/2007-4; $301583 / 2006-4,311396 / 2006-2$ and $150048 / 2010-6)$ for the financial support.

\section{References}

1. McGrath JE, Lyon KR, Davis RM, Texier A and Gungor A. Fine powders of ketone-containing aromatic polymers and process of manufacture. United States Patent 5.357.040. 1994.

2. Cogswell FN. Thermoplastic aromatic polymer composites. A study of the structure, processing and properties of carbon fiber reinforced polyetheretherketone and related materials. Great Britain: ButterworthHeinemann; 1992

3. Gao S.L and Kim J.K. Cooling rate influences in carbon fibre/PEEK composites. Part II: interlaminar fracture toughness. Composites Part A. 2001; 32(6):763-774.

4. Bessonov MI and Zubkov VA. Polyamic acids and polyimides, synthesis, transformations, and structure. Boca Raton: CRC Press; 1993.

5. Mittal KL. Polyimides: Synthesis, characterization, and applications. New York: Plenum Press, 1984. v. 1.

6. Mittal KL. Polyimides: synthesis, characterization, and applications. New York: Plenum Press; 1984. v. 2.

7. Sroog CE. Polyimides. Progress in Polymer Science. 1991; 16(4):561-694.

8. Dubey M and Nema SK. Alloys of polyimides with varying degreee of crosslinking through antimony salts: mechanical properties characterization. Polymer. 1999; 40(21):5947-5951.

9. Ghosh M and Mittal KL. Polyimides: fundamentals and Applications. New York: Marcel Dekker, 1996.

10. Ratta V, Ayambem A, McGrath JE and Wilkes GL. Crystallization and multiple melting behavior of a new semicrystalline polyimide based on 1,3-bis(4-aminophenoxy)benzene (TPER) and 3,3',4,4'-biphenonetetracarboxylic dianhydride (BTDA). Polymer. 2001; 42(14):6173-6186. 
11. Saeed MB and Zhan MS. Effects of monomer structure and imidization degree on mechanical properties and viscoelastic behavior of thermoplastic polyimide films. European Polymer Journal. 2006; 42(8):1844-1854.

12. Srinivas S, Caputo FE, Graham M, Gardner S, Davis RM, McGrath JE et al. Semicrystalline polyimides based on controlled molecular weight phthalimide end-capped 1-3-bis(4-aminophenoxy) benzene and 3,3',4,4' -biphenyltetracarboxylic dianhydride: synthesis, crystallization, melting, and thermal stability. Macromolecules. 1997; 30(4):1012-1022.

13. Chuang SL and Chu NJ. Effect of polyamic acids on interfacial shear strength in carbon fiber/aromatic thermoplastics. Journal of Applied Polymer Science. 1990; 41(1):373-382.

14. Texier A et al. Fabrication of PEEK/carbon fibre composites by aqueous suspension prepregging. Polymer. 1993; 34(4):896-906.

15. Gardner SH. An investigation of the structure-property relationships for high performance thermoplastic matrix, carbon fiber composites with a tailored polyimide interphase. [Tese de Doutorado]. Blacksburg:Virginia Polytechnic Institute and State University; 1998.

16. Nohara LB. Estudo da interface de compósitos termoplásticos estruturais processados a partir de moldagem por compressão a quente e suspensões poliméricas. [Tese de Doutorado]. São José dos Campos: Instituto Tecnológico de Aeronáutica; 2005.

17. Brink AE, Lin MC and Riffle JS. A high-performance electrostatic stabilizer for poly(ether ether ketone) particles. Chemistry of Materials. 1993; 5(7):925-929.

18. Yang PH, Varughese B and Muzzy JD. Flexible thermoset towpregs by electrostatic powder fusion coating. In Proceedings of $36^{\text {th }}$ International
Sampe Symposium and Exhibition; 1991; California. Califórnia: Sampe; 1991. p. 1523-1529.

19. Nohara LB, Kawamoto AM, Takahashi MFK, Wills M, Nohara, EL, Rezende, MC et al. Síntese de um poli(ácido âmico) para aplicação como interfase em compósitos termoplásticos de alto desempenho. Polímeros: Ciência e Tecnologia. 2004; 14(2):121-127.

20. Asao K and Saito H. Polyamic acid and polyimide microfine particles and process for their production. United States Patent 6.187.899. 2001.

21. ASTM International. ASTM D 2344-84: Standard test method for apparent interlaminar shear strength of parallel fiber composites by short-beam method. West Conshohocken: ASTM; 1994.

22. Varner SJ, Vold RL and Hoatson GL. Characterization of polyimides by $13 \mathrm{C}$ and $1 \mathrm{H}$ solid state nuclear magnetic resonance. Solid State Nuclear Magnetic Resonance. 1998; 12(2-3):71-85.

23. Nakamura K, Ando S and Takeichi T. Thermal analysis and solid-state 13C NMR study of crosslink in polyimides containing acetylene groups in the main chain. Polymer. 2001; 42(9):4045-4054.

24. Hasegawa M and Horie K. Photophysics, photochemistry, and optical properties of polyimides. Progress in Polymer Science. 2001; 26(2):259-335.

25. Sauer BB, Hsiao BS and Faron KL. Miscibility and phase properties of poly(aryl ether ketone)s with three high temperature all-aromatic thermoplastic polyimides. Polymer. 1996; 37(3):445-453.

26. Xiaohua K, Fengen T, Hao Tang, Lisong D and Zhiliu F. Miscibility and crystallization behaviour of poly(ether ether ketone)/polyimide blends. Polymer. 1996; 37(9):1751-1755. 